\title{
Satisfaction and Complaints of Patients with Removable Partial Dentures: In Sample at Baghdad City, Iraq
}

\author{
Luma Musa Ibrahim \\ Assistant Lecturer, MsCProsthodontics, College of Dentistry, Alfarahidi University, Baghdad, Iraq
}

\begin{abstract}
Objective: This study examined patients' complain regarding pain on eating, esthetic and speech problems and gag reflex with various types of removable partial dentures (RPDs).

Method: The study sample included 60 RPD wearers (36 females and 24 males) aged between (25-60) years old. Sex, age, occupation, any experience with previous RPDs, and the complaint with RPDs were recorded. Data were analyzed using Chi-square test was applied for comparison among different variables of oral complaints related to removable prosthesis; an independent a sample $t$-test was utilized. A $P$-value $<$ 0.01 was the criterion for rejection of the invalid hypothesis.
\end{abstract}

Results: the results show 60 patients, 16 (47.05\%) were satisfied on acrylic and14 (77.77\%) were satisfied on flexible. And $6(75 \%)$ were satisfied on metallic. The mean level of satisfaction among the three types of RPDs was significantly different $(P<0.01)$. In cases satisfaction between flexible and acrylic RPDs was significantly different. But, between either metal or acrylic, or metal and flexible RPDs no significant differences $(P<0.01)$ were recognized.

Conclusions: Within the limitations of this study, approximately half of cases that tooka removable partial dentures treatment were satisfied with it, showing that the quality of RPDs(in Iraq/Baghdad city) was suitable for patients. Pain in eatingis the most common complaint that shows that dental treatments with RPDs should be provided with care when patients have pain in eating.

Keywords: Patient satisfaction, Removable partial denture, oral complaint, Aesthetics, Dental prosthesis.

\section{Introduction}

The missing tooth structure either caries attacks or injury or other pathological conditions makes researchers and scientists strive to find a suitable material or dental prosthesis to replace the tooth structure in terms of both function and esthetics ${ }^{(1)}$. This is because tooth loss has a negative consequence on facial appearance, speaking and masticatory function and still one of the major oral health problems in the world..$^{(2,3)}$

\section{Corresponding Author: \\ Luma Musa Ibrahim}

Assistant lecturer, MsC Prosthodontics, College of Dentistry, Alfarahidi University, Baghdad, Iraq e-mail: luma.musa@gmail.com
Now a day, there has been an increase in the number of patients who need prosthodontics treatments ${ }^{(4)}$. As a consequence, the demand for complete or partial dentures also has been raised. This is because of increasing the number of older people among the population as the result of rising life expectancy ${ }^{(5)}$.Thus; there are various alternative treatment modalities available for replacement for partially edentate patients. These treatment involve prosthesis supported by implants, bridges supported by teeth, and removable partial dentures (RPDs) ${ }^{(6,7)}$.

Therefore, choices, like as dental implants, can be not easy to apply because of general and/or patient preferences, oral limitations and financial issues. ${ }^{(8,9)}$

Many studies in different countries have found that the cost of treatments plays a crucial role during the construction of dental prosthesis for partially edentate 
patients ${ }^{(10,11)}$. For these reasons, the removable partial denture is still the most common way of restoring the missing teeth ${ }^{(12,13)}$.

A survey of 260 Iraqi volunteers based on 2018, whose loosing teeth had been effectively restored with RPDs, It is believed that the quality of prosthodontics treatments may affect significantly on quality of life related to oral health $^{(14)}$.

Despite easy construction, managing (RPDs), minimally invasive treatment choice, reasonably low cost but (RPDs) are still related to many oral complains such as mastication, speaking difficulties, pain and esthetic concerns ${ }^{(15)}$. The satisfaction of patients witha prosthesis therapy has become an increasingly significant factor in prosthetic treatment ${ }^{(16)}$. Thus, many studies have examined the relation between RPDs and cases satisfaction and their dentures quality ${ }^{(16,17)}$. It is believed that the quality of prosthodontic treatments may affect significantly on quality of life related to oral health ${ }^{(18,19)}$.

It is not easy to expect the patient's satisfaction with RPDs therapy because it is a multifactor characteristic. It has been reported that patients' attitude towards RPDs, patient's personality, any contact with the previous RPD, patients believe the RPDs therapy or forced to do this treatment as well as denture design and fabrication procedures are related to RPDs satisfaction. In addition, there are other important factors, which are strongly correlated with RPDs acceptance by the patients such as, retention, stability, chewing ability and esthetics ${ }^{(20)}$. However, there is a gap in the information on patients' satisfaction and complaint among (RPDs) wearers in

Baghdad city, Iraq. This study aims to explore the patient's satisfaction with comfort or presence of pain, esthetic, retention, mastication, as well as speaking with RPDs.

Various bases have been progressed formaking RPD. Flexible,acrylic polymers (polymethyl methacrylate [PMMA]) and metallic (chrome cobalt alloys) materials. And due to the noticeablycheap, manipulated easily with utilization of low-pricetools, acrylic RPDs are the most accepted material for denture framework creation. Therefore, in flexibility term, nylon-derived denture base material make arevolution as afunctional alternative material to overcome some restriction and came backto acrylic dentures. ${ }^{(21,22)}$

Correspondingly, in interview bytelephone with 260Iraqi male and femalecases who had got RPDs atCollege of dentistry/Baghdad University, college of dentistry/Al-Anbar Universityand private clinics.

Even though RPDs are areversible and a non-invasive therapy, with a suitableprice and easy oral hygiene method in most cases, they are relatedtonumber of oral complaints, like speech problem, pain,mastication, as well as esthetic issues. ${ }^{(23,24,25)}$ Therefore, this survey aimed to detect the complaints and satisfaction level among patients using the three types of RPDs in Baghdad/Iraq.

\section{Materials and Method}

This survey done at three places (College of dentistry/Baghdad University, College of dentistry/AlAnbar University, private clinics)the dental data was searched for surveying(cases) participants the following criteria forcases included: the age group was(from 25 to 60 ), telephonic communication, complete andaccurate dental data, and available therapy plan of action details. Cases with chronicdisorder or systemic diseases which couldgive aneffect oral health, likeoral cancer and uncontrolled diabetes, were excluded.

All of 260 cases treated with RPDs from January 2018 to January 2019 , these cases got interviewed by phone. 100 cases of them took acall. Of the 100 , sixty cases ( 24 female and 36 male cases) agreed to be a participant in this study asseen in Figure 1. two questions were asked to each participant over the phone interview to detect their complaints and satisfaction levels of with RPD wearers, speaking, eatingas well as esthetics. The first question is "Do you have any complaints (comments)" The second question was: "how satisfied are you with the RPD?" cases (sex and age) and information on the type of RPD (acrylic,flexible, or metal) demographics were obtained from the cases dental data. 


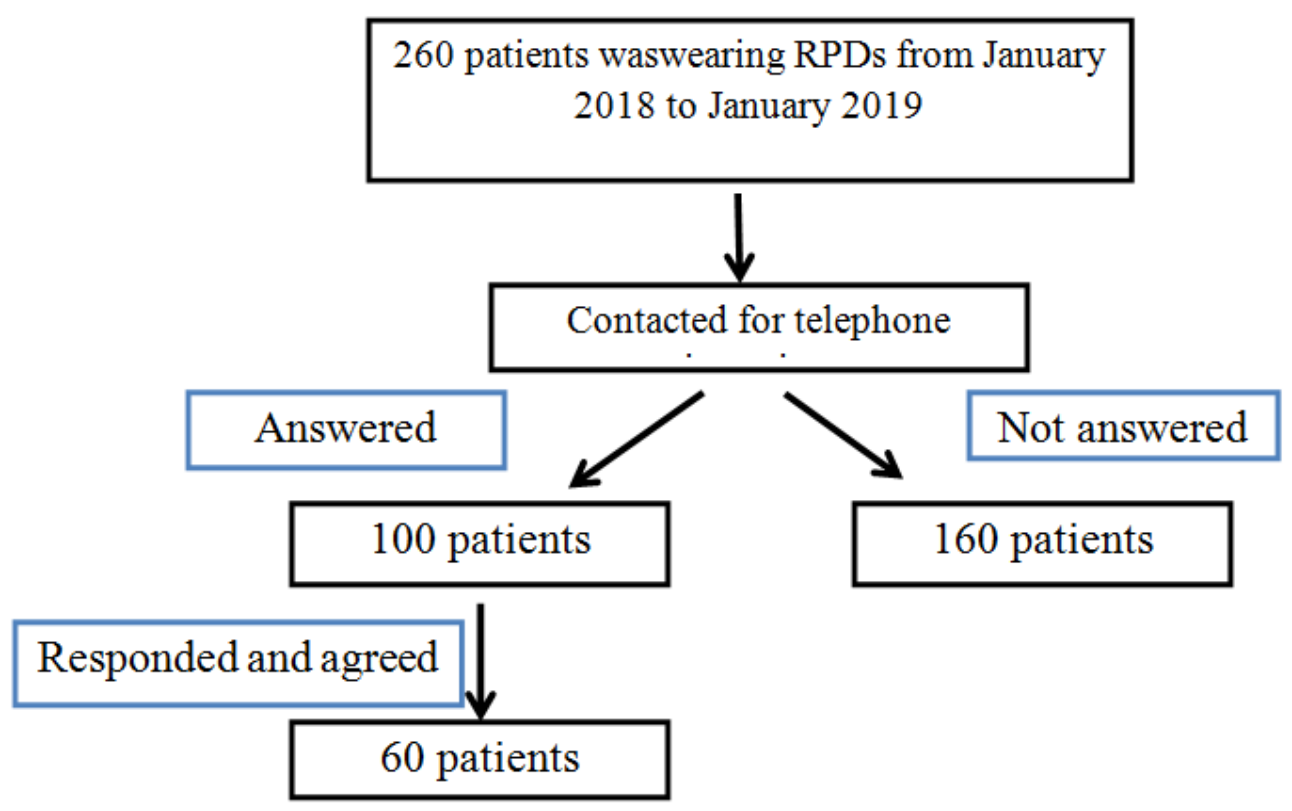

Figure (1) Patient's participation in study.

Statistical Analysis: The resulting data were entered into a statistical software program (Statistical Package for the Social Sciences, version 16.0; SPSS), which was used for all the statistical analyses. Mean \pm standard deviation (SD) counts and percentages are used for recording variables. Chi-square test was applied for comparison among different variables of oral complaints related to removable prosthesis; a sample $t$-test was utilized. A $P$-value $<0.01$ was the criterion for rejection of the invalid hypothesis. Data were collected from cases electronic files into a Microsoft Excel 2010.

\section{Results}

For the 260 patients who wear RPD from the three places from January 2018 to January 2019. Sixty cases (24 male and 36 female cases) participated in this survey with three types of RPDs. 34(56.66\%) wore acrylic RPDs, 18 (30\%) had flexible RPDs, and 8 (13.33\%) wore metallic RPDs; variable information was obtained from all patients. The mean $\pm \mathrm{SD}$ age of the cases was $49.8 \pm 8.3$ years for wore acrylic, $47.8 \pm 8.9$ years for wore flexible and $47.2 \pm 7.7$ years for wore metallic (range: 25-60 years) as shown in Table 1.

In table 2 Shows, the symptoms were: $23(38 \%)$ pain in eating, $6(10 \%)$ esthetic problems, $16(26.66 \%)$ problems in speech, and $10(16.66 \%)$ gag reflex where 5(8.33) only had no complaint.

Table 3 shows 60 patients, $16(47.05 \%)$ were satisfied on acrylic and $14(77.77 \%)$ were satisfied on flexible. And 6 (75\%) were satisfied on metallic.

The mean level of satisfaction among the three types of RPDs was significantly different $(P<0.01)$. In cases satisfaction between flexible and acrylic RPDs was significantly different. But,between either metal or acrylic, or metal and flexible RPDs no significant differences $(P<0.01)$ were recognized.

Table 1 Patient's demographics

\begin{tabular}{|l|c|c|c|c|}
\hline \multirow{2}{*}{ Type of RPD } & \multirow{2}{*}{ No. of Patients } & \multicolumn{2}{|c|}{ Gender } & \multirow{2}{*}{ Age (Mean \pm SD) } \\
\cline { 3 - 5 } & & Female & 13 & $49.8 \pm 8.3$ \\
\hline Acrylic & 34 & 19 & 8 & $47.8 \pm 8.9$ \\
\hline Flexible & 18 & 12 & 5 & $47.2 \pm 7.7$ \\
\hline Metal & 8 & 5 & $\mathbf{2 4}$ & - \\
\hline Total & $\mathbf{6 0}$ & $\mathbf{3 6}$ & & \\
\hline
\end{tabular}


Table 2 Patient's symptoms and complaint

\begin{tabular}{|l|c|c|c|c|c|}
\hline \multirow{2}{*}{ Type of RPD } & \multicolumn{5}{|c|}{ Symptoms } \\
\cline { 2 - 6 } & Pain on eating & Esthetic problems & Speech problems & Gag reflex & No complaint \\
\hline Acrylic & $14(41 \%)$ & $3(9 \%)$ & $10(30 \%)$ & $7(20 \%)$ & 0 \\
\hline Flexible & $8(44 \%)$ & $3(17 \%)$ & $5(28 \%)$ & $2(11 \%)$ & 0 \\
\hline Metal & $1(12.5 \%)$ & 0 & $1(12.5 \%)$ & $1(12.5 \%)$ & $5(62.5 \%)$ \\
\hline Total & $\mathbf{2 3}$ & $\mathbf{6}$ & $\mathbf{1 6}$ & $\mathbf{1 0}$ & $\mathbf{5}$ \\
\hline
\end{tabular}

Table 3 Patient's satisfaction

\begin{tabular}{|l|l|c|c|}
\hline \multirow{2}{*}{ Type of RPD } & \multirow{2}{*}{ No. of patients satisfied } & \multicolumn{2}{|c|}{ P values } \\
\cline { 3 - 4 } & & Flexible & Metal \\
\hline Acrylic & $16 / 34$ & 0.03 & 0.15 \\
\hline Flexible & $14 / 18$ & - & 0.87 \\
\hline Metal & $6 / 8$ & - & - \\
\hline
\end{tabular}

${ }^{*} P$ value $<0.01$

\section{Discussion}

In this study observed the rate of complaints and satisfaction among sixty cases wearing three kinds of RPDs in Baghdad city/Iraq. According to the result of this survey indicates that the approximately half of cases were fulfilled with their RPDs. That result was in agreement with other surveys on RPDs. ${ }^{(26,27)}$ the mean age of RPD wearers in this study was 48.2 years (range: 25-60). Others studies also had the same age range. $(28,18,19)$

Flexible RPDs are a goodtherapy choice for partially edentulous cases due to their definitely better esthetics given by bases that copygums and teeth, also due tothem being more comfortable for cases with changing oral tissue, severe cases with microstomia, as well asdecrease of function. ${ }^{(22)}$ and because of that, flexible RPDs can appropriately satisfy patients displeased with the common recovery therapy since they give an excellentfix for the cases esthetics or physical limitations. ${ }^{(29)}$ It is in agreement with Sharma \& Shashidhara (2014), flexible RPDs produce acceptable outcomes but short duration. ${ }^{(22)}$ due to that flexible RPDs haven't been commonly used as a substitute material for denture fabrication as shown in this survey .

It is observed that patient satisfaction between different RPDs materials was varied. Acrylic resin (PMMA) RPDs were had a lowest satisfaction level, followed by metallic (chrome cobalt alloys), while the higher level of satisfaction was shown inflexible nylonbase material. These results are in agreement with those of Yoshida et al. (2011), who indicate that cases withacrylic RPDs have had a lower satisfaction levels than of those with flexible nylon-base material RPDs. ${ }^{(30)}$ in spite of these results the Iraqi samples not prefer flexible RPDs because of its low duration.

Moreover, shown that a low satisfaction levels with acrylic resin base in comparison with metallic base, acrylic resin base RPDs were frequently used in this survey 34 (56.66\%). These results are similartoother studies in countries in Middle East. Ismail and Hussien (2009) proposed that over $97 \%$ of Iraqi patients wore acrylic RPDs. ${ }^{(31)}$ in agreement with Rahdi et al.the Kingdom of BahrainIndicates that $89 \%$ of RPDsdetermine were acrylics. ${ }^{(15)}$

Although, RPDs are commonly used for the substitute of losingteeth, The most frequent complication have been reported among different countries . ${ }^{(27)}$ In this survey, pain during eating followed by speech problems are the most common complaints for RPD wearers in Iraqi cases,thatare in agreement with Akeel, in KSA, (2010).

Additionally, this survey was managed within one year of RPD utilization, that may be seen asnot enoughtime to predict the accurate levels of case 
satisfaction. a sample of KSA cases, Akeel et al. (2010) indicated that $36 \%$ of RPD wearers discontinued using the RPDs one year after wearing it. ${ }^{(23)}$ It was proposed that an observational study based on frequent recall time had to be developed.

\section{Conclusion}

Within the limitations of this study, approximately half of cases that tooka removable partial dentures treatment were satisfied with it, showing that the quality of RPDs(in Iraq/Baghdad city)was suitable for patients. Pain in eatingis the most common complaint that shows that dental treatments with RPDs should be provided with care when patients havepain in eating.

Ethical Clearance was obtained from Alfarahidi University, Baghdad, Iraq.

\section{Conflict of Interest: None}

Funding: None

\section{Reference}

1. Hewa A. Salih, Jwan R. Abdulazeez, Tanya H. Hama Faiq, Mohammed A. Mahmood, Rukhosh H. Abdalrahim,- Patient Complaints and Satisfaction with Removable Partial Dentures Therapy in Sulaimani City, Iraq,Sulaimani Dent J. December 2019 Vol 6(2)

2. Gil-Montoya JA, de Mello AL, Barrios R, GonzalezMoles MA, Bravo M. Oral health in the elderly patient and its impact on general wellbeing: a nonsystematic review. Clin Interv Aging. 2015;10:461-67.

3. Kassebaum NJ, Bernabe E, Dahiya M, Bhandari B, Murray CJ, Marcenes W. Global burden of severe tooth loss: a systematic review and metaanalysis. J Dent Res. 2014;93(7):20S-28S.

4. United Nations Population Division. World Population Aging. The 2015 Revision. New York: United Nations, 2015.

5. Yang Y, Zhang H, Chai Z, Chen J, Zhang S. Multiple logistic regression analysis of risk factors associated with denture plaque and staining in chinese removable denture wearers over 40 years old in Xi' an - a cross-sectional study. PLoS ONE. 2014;9(2):e87749.

6. Stilwell C. Risk management in clinical practice. Part 6b. Identifying and avoiding medico-legal risks in removable dentures. Br Dent J.2010;209(7):33950.

7. Furuyama C, Takaba M, Inukai M, Mulligan R, Igarashi Y, Baba K. Oral health-related quality of life in patients treated by implant-supported fixed dentures and removable partial dentures. Clin Oral Implants Res. 2012;23(8): 958-62.

8. Stilwell C. Risk management in clinical practice. Part 6b. Identifying and avoiding medico-legal risks in removable dentures. BDJ. 2010;209(7):339-350.

9. Furuyama C., Takaba M., Inukai M., Mulligan R., Igarashi Y., Baba K. Oral health-related quality of life in patients treated by implant-supported fixed dentures and removable partial dentures. Clin Oral Implants Res. 2012;23(8):958-962.

10. Sakka S., Baroudi K., Nassani M.Z. Factors associated with early and late failure of dental implants. J Investig Clin Dent. 2012;3(4):258-261.

11. Leles CR, Martins RR, Silva ET, Nunes MF. Discriminant analysis of patients' reasons for choosing or refusing treatments for partial edentulism. J Oral Rehabil. 2009;36(12):909-15.

12. Özkurt-Kayahan Z,Tomruk CÖ, Kazazoğlu E. Partial edentulism and treatment options. 7 tepeklinik. 2016:31-36.

13. Charyeva OO, Altynbekov KD, Nysanova BZ. Kennedy Classification and treatment options: A study of partially edentulous patients being treated in a specialized prosthetic clinic. J Prosthodont. 2012;21(3):177-80.

14. Shafaei A. Correlation between socioeconomic status and different types of prosthetic modalities in hail region, Saudi Arabia. Dent Oral Craniofacial Res. 2016;2(5):344-348.

15. Radhi A., Lynch C.D., Hannigan A. Quality of written communication and master impressions for fabrication of removable partial prostheses in the Kingdom of Bahrain. J Oral Rehabil. 2007;34(2):153-157.

16. Yeung A., Lo E., Clark R., Chow T. Usage and status of cobalt-chromium removable partial dentures 5-6 years after placement. J Oral Rehabil. 2002;29(2):127-132.

17. Mohsen K. Aljabri, BDS, Tamer O. Ibrahim, MDand Rayan M. Sharka, BDS,Removable partial dentures: Patient satisfaction and complaints in Makkah City, KSA Received 20 December 2016; revised 27 February 2017; accepted 7 March 2017; 
Available online 25 April 2017

18. Pellizzer E.P., Almeida D.A., Falcón-Antenucci R.M., Sánchez D.M., Zuim P.R., Verri F.R. Prevalence of removable partial dentures users treated at the Aracatuba Dental School -UNESP. Gerodontology. 2012;29(2):140-144. [PubMed] [Google Scholar]

19. AL-Dwairi Z. Need and demand of removable dentures by Jordanian adults and relationship to socioeconomic factors. J Oral Hyg Health. 2013;1(2):113. [Google Scholar]

20. Shala KS, Dula LJ, Pustina-Krasniqi T, Bicaj T,Ahmedi EF, Lila-Krasniqi Z, Tmava-DragushaA. Patient's satisfaction with removable partial dentures: retrospective case series. Open Denti J. 2016;10:656-63.

21. Singh J., Dhiman R., Bedi R., Girish S. Flexible denture base material: a viable alternative to conventional acrylic denture base material. Contemp Clin Dent. 2011;2(4):313.

22. Sharma A., Shashidhara H.S. A review: flexible removable partial dentures. J Dent Med Sci. 2014;13(12):58-62.

23. Akeel R. Usage of removable partial dentures in Saudi male patients after 1 year telephone interview. Saudi Dent J. 2010;22(3):125-128.

24. Khan M., Khan A. Oral complaints and level of satisfaction among the removable denture wearers. Pak Oral Dent J. 2015;35(1)
25. Shams A., Tavanafar S., Dastjerdi M.R., Chaijan K.A. Patient satisfaction and complication rates after delivery of removable partial dentures: a 4-year retrospective study. SRM J Res Dent Sci. 2015;6(4):225-229.

26 -Wu J., Yang Y., Wang C., Lee H., Du J. Effects of denture maintenance on satisfaction levels of Taiwanese elderly using removable partial dentures: a pilot study. Gerodontology. 2011;29(2):458-463.

27. Knezović Zlatarić D., Čelebić A., ValentićPeruzović M., Ćelić R., Filipović-Zore I., Baučić M. The satisfaction with the removable partial denture therapy in the Croatian adult population. Coll Antropol. 2000;24(2):485-494.

28. Siqueira G.P., Dos Santos M.B., Santos J.F., Marchini L. Patients' expectation and satisfaction with removable dental prosthesis therapy and correlation with patients' evaluation of the dentists. Acta Odontol Scand. 2013;71(1):210-214.

29. Simone Guimarães Farias, Altair Antoninha Del Bel; Flexible resins: an esthetic option for partially edentulous patients, RGO, Rev GaúchOdontol, Porto Alegre, v.63, n.1, p. 81-86, jan./mar., 2015.

30. Yoshida E., Fueki K., Igarashi Y. A follow-up study on removable partial dentures in undergraduate program: Part I. Participants and denture use by telephone survey. J Med Dent Sci. 2011;58:61-67.

31. Ismail I.J., Hussein B.M. Frequency and suppliers of removable partial dentures among group of Iraqi population. J Bagh Coll Dent. 2009;21(2):49-54. 